\title{
Understanding consumer behavior in the multimedia context: incorporating gamification in VR-enhanced web system for tourism e-commerce
}

\author{
Yu-Teng Jang ${ }^{1} \cdot$ Pei-Shan Hsieh ${ }^{1}$
}

Received: 7 September 2020 /Revised: 10 April 2021 / Accepted: 3 June 2021 /

Published online: 24 June 2021

(C) The Author(s), under exclusive licence to Springer Science+Business Media, LLC, part of Springer Nature 2021

\begin{abstract}
This study aims to investigate how gamification and virtual reality (VR)-enhanced web services can be integrated to influence consumer behavior in the context of tourism ecommerce. A gamified VR-enhanced tourism web system (VRTWS) was designed and developed for this investigation, while a research framework with 12 hypotheses was proposed and empirically tested by adopting PLS-SEM approach to analyze 208 valid data collected from survey. The results reveal that both Enjoyment and Activation in Gamification significantly and positively affected Media Richness. Additionally, Media Richness significantly and positively affected both Usefulness and Ease of Use in using VR technology with gamification. Also, a user's Perceived Value is not only positively affected by Usefulness and Ease of Use but also Interactivity and Immersion in a gamified VRTWS. Immersion was found to be positively affected by Presence. Through the positive effect on Satisfaction, user's Perceived Value had positive effect on the Intention toward adoption. The proposed gamified VRTWS and the study results with implications are expected to be referenced by the researchers and practitioners for managing incorporation of gamification into designing, developing, and managing their VR-enhanced service in tourism e-commerce.
\end{abstract}

Keywords Multimedia technology adoption · Gamification · Electronic commerce $\cdot$ User behavior · Partial least squares (PLS)

Yu-Teng Jang

ytjackyjang@thu.edu.tw

Pei-Shan Hsieh

psh1983@thu.edu.tw

1 Department of Business Administration, Tunghai University, Taichung City, Taiwan 


\section{Introduction}

Although COVID-19 pandemics with various prevention procedures have temporarily damaged the tourism industry in many countries, tourism has shown its continuous growth in the past few years as it was recognized as a substantial and relatively green industry in the world [4]. The gross output value of the tourism industry has accounted for $10.4 \%$ of the global GDP based on the statistics of World Travel and Tourism Council 2018. Its economy has been reported to grow by $4.6 \%$ (compared with the previous year) and provide various employment opportunities in tourism sector [108]. Also, the number of employees employed in the tourism industry has been reported to account for around $9.9 \%$ of the global employed population. All of these facts indicate that the huge demand and service capacity can be the foundation of tourism industry in contributing to creating a competitive environment for tourism service providers in running their business. Meanwhile, due to the increasing Internet adoption and the popularity of online shopping in the past decades, the development of electronic commerce (ecommerce) has demonstrated a steady growing trend globally [115]. In this regard, although tourism traditionally has been identified as a "brick-and-mortar" industry, many traditional travel agencies have stepped into establishing, launching, and operating their websites to create an online channel to expand and extend their service scope [11, 21, 49]. Emerging iconic startups such as Airbnb and Klook are providing various tourism products online and serving travelers worldwide through their unique e-commerce models and online service systems [2, 60]. In fulfilling users' various demands, e-commerce has contributed toward making the tourism industry a more competitive market. Today, the evolution and advancement of information and communication technologies (ICTs) have driven the tourism industry to be largely influenced and reshaped in terms of providing the information of and selling the tourism products to the users online. Thus, managers in tourism industry have kept thinking of and exploring possible approaches in creating value for attracting, engaging and retaining their customers in multi-channel retailing context $[49,97]$.

With virtual reality (VR) becoming more affordable and accessible with every passing year, it has been considered to be one of the promising technological elements in various application domains [96]. Industries such as video games [74], medical training [13], education [87], TV [8], and entertainment [88] are striving to apply VR technology to their conventional business and service models to provide their customers a different and novel experience. However, the research and development of VR in the tourism industry is still in a preliminary stage. Recent research has studied the context of using VR in providing remote telepresence such that a user can see, for example, the antiques in museums and visit heritages for the purpose of protection from damage [56]. This perspective is different from the one in tourism e-commerce, in which the application of VR is designed to attract as many visitors as possible and provide users (or potential travelers) a different experience for previewing the tourism attractions, thus increasing conversion rate of buying the tourism products for real traveling (e.g., taking planes to Japan and enjoying local cuisines) instead of merely in VR. Indeed, as highlighted by Guttentag [38], integrating VR into tourism sectors will present new challenges. The application and development in creating pure VR experience in the tourism sector remain challenging while new combinations deserve further investigation [38]. Properly combining promising digital technology with psychological elements would help formulate marketing strategies and design marketing systems in attracting users for adoption [51, 104]. Therefore, inspired by the popularity of gamification (as gameful experience has been recognized as one of the important elements in bringing enjoyable and positive emotions in online learning) [30, 42], our study 
firstly designed and developed a gamified VR-enhanced tourism web system (VRTWS) for exploring how gamification can play a role with regard to consumer behavior in such a tourism e-commerce context. This research was conducted with the following as its aims: (1) to examine how and why potential tourists who are those younger generations accept the delivered marketing information when the intention of tourism service providers is the development of VRTWS for publicizing their wares; (2) to explore whether a gamified VRTWS can help tourism service providers understand potential tourists' intention to visit the tourism destination in this digital world; and (3) to verify gamification-and-VR enriched the ordinary tourism websites' marketing in today's highly competitive and fast-changing etourism environment.

\section{Literature review}

\subsection{Viewing VR and gamification as new opportunity for tourism e-commerce}

The tourism industry in the digital era has been widely affected by the Internet and technological advancements in all of its many forms [11]. By adopting a "cyber-enhanced retailing" e-commerce model, traditional travel agencies have been enabled to establish online websites that extend their service boundaries as well as provide expanded accessibility and timely updated product/service information to consumers [54, 97]. Inspired by the continuous evolution of advanced ICTs, some websites have started to add advanced technological elements, for instance $360^{\circ}$ photos and displays. Although $360^{\circ}$ photos and displays can provide richer information about the tourism attractions to visitors, the perceived value can still be limited because of certain constrains on control in the interaction process between the users and tourism service provides [46]. In addition to looking for the experience of seeing the attractions online, users may start to seek a positive experience when they are adopting and using new systems or services. As a negative experience may reduce the willingness of users' intention of adoption, researchers and practitioners continue to devote their efforts to exploring feasible approaches of increasing positive experience and reducing negative effects by designing suitable service systems and investigating the pros and cons and relationships between the important factors of using such systems [3, 25, 44, 48, 84]. Meanwhile, as gamification and VR technology have shown their promising potential to the academic and practical fields [30, 42], this study firstly combines them together to design and construct the investigated tourism service to form a gamified VRTWS in the study. Gamification has been recognized as an emerging and important research issue in various research fields. In marketing, consumers are fond of interesting marketing messages and campaigns. A good gameful experience may provide a better user experience in the interaction with the major players in the communication system, which may lead to an elevated brand image, a better engagement rate, and even an enhanced conversion rate. However, gameful experience may not be easy to define as it is multidimensional in nature [30]. In the study conducted by Eppmann et al. [30], gameful experience is considered as a kind of psychological outcome of using a gamified application, while gamification is a more technical process. Of the latter seeks to enhance an application by adding game elements in a context where there was no game. Following the definition and gameful experience scale [GAMEX] proposed by Eppmann et al. [30], our study adopted and incorporated three major measurement scales (i.e., enjoyment, creative thinking, and 
activation) into our research model in exploring the manner in which gamification can be used to influence consumer behavior when it comes to a VRTWS.

\subsection{Relationship between enjoyment in gamification and media richness}

Enjoyment has been considered as an important element in the communication process between information senders and receivers [76]. Prior studies argued that positive emotions, such as enjoyment or happiness, could be generated in the process of entertaining [29, 95, 111]. Also pointed out by prior studies, positive emotional experiences (particularly enjoyment) would be highly important for gameful experience [30, 43]. Why is enjoyment so important? Part of the main reasons is that it is highly possible that the positive feeling of enjoyment received by the consumers would turn to create positive impact on their attitude toward the advertised goods, services, or brands [28, 77]. Providing users the feelings of enjoyment would help capture their attention, and a great deal of involvement and pleasure during the interaction with a delivered medium would result in positive feelings and emotions in users' subject perception [80]. By the means of providing users funny and entertaining messages with useful information in mobile marketing campaigns has been argued to be more likely to increase their purchase intention [93]. In our study, the operational definition for the dimension of "enjoyment in gamification" refers to the extent to which a user's enjoyable feelings about the games in VR.

In media richness domain, media richness theory (MRT) was proposed by the scholars Daft and Lengel [24]. Media richness refers to the communication ability provided by specific media in a certain period of time. A higher level of media richness is reached if the selected media can deliver relatively richer and easy-to-understand information [24, 73]. If the delivered information is relatively vague, then the media richness tends to be low as the receivers (e.g., users or consumers) would need to take more effort to interpret and understand the delivered information $[24,73]$. MRT argues that all communication media may vary in their ability in enabling users in communication [26]. The extent of such an ability is known as a medium's "richness." In this study, we incorporated the gamification (by designing games for providing gameful experience) into the VRTWS. Users (such as consumers) may experience a different way in receiving information compared with a traditional tourism website. Enjoyment, the element of gameful experience, was postulated to significantly and positively affect media richness in the study. Therefore, our first hypothesis is postulated as:

H1: User's enjoyable feeling from the gamified media would positively influence his/her perceived richness regarding the media.

\subsection{Relationship between creative thinking in gamification and media richness}

Agogué et al. [1] explored the impact of gamification on learning has shown the possibility of improving learning by the process of gamification. As an attempt, Hakak et al. [42] also proposed a cloud-assisted method in applying gamification to learning. Through gamification, the communication efficiency in learning would be increased. Creativity, defined as the ability to change existing things in prior literature, may be fostered by the process of gamification [57]. Through gamification, players' imagination may be stimulated, thus making them more creative [30]. As creative thinking is one of the major gameful experience scales adopted in the 
study [30], it is postulated to positively influence media richness in the proposed context of a VRTWS.

H2: User's feeling of creative thinking from the gamified media would positively influence his/her perceived richness regarding the media.

\subsection{Relationship between activation in gamification and media richness}

The dimension of activation is introduced in the study of constructing and validating a gameful experience scale [GAMEX] conducted by Eppmann et al. [30]. Through gamification, players may feel excited, energized, and activated. Gamification has been argued to have the ability to increase the motivation of the players in the interaction process [30]. With gamification, participants' willingness to join and act would also be increased. Compared with ordinary tourism websites (e.g., https://en.liontravel.com/) in which users only can use the browser on their PCs or mobile devices to check tourism information, the proposed VRTWS allows users to experience free exploration and interact with the system by performing gameful tasks, thus increasing the motives and willingness of the players in participating in VRTWS. Consequently, activation in gamification is postulated to positively affect media richness.

H3: User's feeling of activation from the gamified media would positively influence his/her perceived richness regarding the media.

\subsection{Relationships between media richness, usefulness, and ease of use}

Suggested by Davis [25], "usefulness" and "ease of use" are two important factors in association with adopting new information technology. In addition to the attitude toward adopting new technology, "usefulness" and "ease of use" have been also widely adopted to study users' intention in adopting new types of information, interaction, and business models [5, 25, 61, 63, 91]. "Usefulness," in general, refers to the extent that a user believes that his/her performance would be enhanced by adopting a specific approach (such as a system), whereas "ease of use" generally refers to the degree to which a user believes that using a particular system would be free of effort [25]. If a system is too difficult to use, the performance benefits of its usage will be outweighed by the effort of using it. In general, users are concerned with both usefulness and ease of use in choosing and adopting new technologies in meeting their specific goals. Based on the perspective from media richness, the level of media richness tends to be higher as the delivered information is informative and clear [24]. In a higher media richness context, the information receivers would take less effort to interpret and understand the delivered information.

Jacob, Guéguen, and Petr (2010) examined how media richness affected a tourism website, and found out that the greatest degree of media richness (i.e., $360^{\circ}$ navigation and street sounds) resulted in the most positive evaluations of the tourism website [52]. Furthermore, Lim and Benbasat (2000) viewed e-book readers as a new type of electronic media, and observed that media richness (video-based vs. text-based representation) positively affects perceived usefulness [67]. Saeed and Sinnappan (2010) proposed that the media richness of podcasts and Second Life are positively related to the ease of use [92]. Similarly, Heinrichs et al. (2008) revealing that media richness is positively related to the usefulness and ease of use 
about the e-learning [45]. Therefore, different media combinations (presentation types) represent different levels of media richness, which could then be associated with the perceived usefulness of the e-learning experience [67]. In addition, some studies have also shown the significant effect of perceived media richness on usefulness [70] and ease of use [16] of ecommerce and e-learning systems respectively.

Considering our study context is different from conventional tourism websites in the way of delivering information, the proposed gamified VRTWS contains and conveys richer information in interacting with users, which allows the users to receive more comprehensive and timely information. In addition, VRTWS also provides the users a certain degree of flexibility in controlling the interaction and communication with the system, and thus may increase the perceived "usefulness" and "ease of use." Therefore, hypotheses, H4 and H5, are postulated as:

H4: User's perceived richness regarding the media positively influences his/her perceived usefulness.

H5: User's perceived richness regarding the media positively influences his/her perceived ease of use.

\subsection{Relationships between usefulness, ease of use, and perceived value}

Derived from technology acceptance perspective [25], when an individual feels that a system would help them perform better while being easy to use, the perceived usefulness as well as the perceived ease of use would increase. It is argued that the adopted technology (e.g., system) as well as the business would bring value and benefits to the users when the perceived usefulness and ease of use are high [5, 25]. Value is the overall assessment on the effectiveness (e.g., the expected performance) and the cost (e.g., time and effort) regarding the usage of a particular product, service, system, or application [20, 84, 113]. In addition, perceived value is a relatively psychological dimension that is measured by users' own opinions instead of researchers' observations [33]. Prior study has shown the positive relationship between useful information and perceived value [10]. Useful information has been identified as valuable even when delivered in an online advertising context [59]. In addition, using emerging technology such as VR in movement therapy on the functional recovery of the upper extremity for subacute stroke patients has been considered useful and valuable [20]. Similarly, ease of use has been argued to have a significant impact on the adoption of e-commerce information system and new technologies $[34,94]$. On the basis of prior literature, we considered the usefulness and ease of use as two important dimensions that may positively influence the perceived value in our study context. Thus, hypotheses H6 and H7 are postulated as:

H6: User's perceived usefulness positively influences his/her perceived value. H7: User's perceived ease of use positively influences his/her perceived value.

\subsection{Relationship between interactivity and perceived value}

Interactivity was argued as a part of evolution ontology and epistemology of new communication technologies in general, particularly of computer systems as media 
[85]. It naturally exists in a two-way communication and interaction between users and systems. More specifically, interactivity refers to the extent to which a user can participate in modifying the content and form of a mediated environment in real time $[66,75$, 99, 109]. Marketers usually add interactive elements to formulate their marketing strategies and design marketing systems in attracting potential users as interactive marketing campaigns have proven helpful in drawing consumers' attention and increasing the engagement rate [51, 104]. Lee \& Kim (2021) proposed interactivity is defined as twoway user-machine interaction with timely reactions under the user's control, and interactivity can assist user decision-making in the VR tourism context [62]. A higher degree of interactivity would provide users better experience in interacting with the system with better information control in the two-way communication process, thus enhancing the value perceived by the users $[69,71]$. Moreover, previous studies have examined the relationship between interactivity and values in the e-retailing context [112]. Also, interactivity has positive effects on users' perceived value of websites [18, 102]. As the proposed VRTWS enables users to explore the VR tourism attraction and communicate with the system in a relatively interactive way, the perceived value is expected to be positively influenced by interactivity. Therefore, hypothesis H8 is postulated as:

H8: Interactivity positively influences perceived value.

\subsection{Relationship between presence and immersion}

Presence is the concept firstly proposed to illustrate the long-distance real object in the remote operating system. Specifically, presence refers to the extent to which an individual's experience of an environment from the media $[58,64,99]$. In other words, presence describes the realism level perceived by the users based on their relative information on the physical environment as well as indirect environment (such as in a VR context). In addition, a prior study has pointed out the importance of presence in attaining better flow experience and effectiveness in constructing tourism websites [98].

Immersion is another important dimension in the gamified environment [55]. It is a subjective and short-lived experience and the state of an individual in which he or she would concentrate his or her attention on a smaller scale; at the same time, the irrelevant perceptions would tend to be ignored while a sense of control in manipulating the perceived environment would be created [55, 105]. With users' consciousness fully integrated with the immersion, users would tend to completely focus on one thing and forget about distractions. Additionally, under such an immersive state, people would tend to ignore the lapse of time [105]. Moreover, a prior study argued that a higher degree of realism would bring users a higher level of immersive experience in online game contexts [106]. Furthermore, Mütterlein (2018) confirmed that presence has a direct and positive influence on immersion by using HTC Vive devices as VR equipment and VR contents ("The Body VR" or "VR The Diner Duo") [79]. As our study considers the plausibly positive linkage between presence and immersion in the proposed context of gamified VRTWS, hypothesis H9 is consequently postulated as:

H9: Presence positively influences immersion. 


\subsection{Relationship between immersion and perceived value}

In the research domain of gaming, the concept of immersion partly overlaps with flow in terms of creating a perceived distortion of time and challenging a person to get, and stay, involved in a task [55]. However, flow particularly refers to an optimal experience (that is usually an extreme psychological mode such as a basketball player suddenly got the right feeling and scored high points in a short period of time), whereas immersion is an experience describing the users' attention to tasks through degrees of engagement [23, 55]. Many game players seek an immersive experience when playing games. As immersive experience is identified as being important in VR contexts [55] and it is postulated that immersion would provide users a good experience in the environment, they can focus on what they are interested in without dealing with external disturbances, thus enhancing perceived value for users. Gilmore and Pine (2007) identified the perceived value as a consequence of immersion in the field of m-commerce [36]. In addition, Ltifi (2018) described perceived value enables a consideration of all emotional experience that it seems particularly relevant with immersion in an online experiential environment. Furthermore, Ltifi (2018) confirmed that immersion positively influences the perceived value of m-services [72]. Similarly, Charfi (2014) verified that the perceived value is strongly influenced by immersion in the experiential environment of the site [14]. Consequently, hypothesis $\mathrm{H} 10$ is postulated as:

H10: Immersion positively influences perceived value.

\subsection{Relationship between perceived value and satisfaction}

Perceived value reflects the overall assessment on the tangible/intangible benefits and costs perceived by the consumers. That is to say, perceived value is the judgment of costs and benefits that is based on people's subjective pair [20, 84, 100, 113]; consumers tend to consider a product or service as valuable on the basis of their judgment of whether the adopted product or service can fulfill their needs $[9,83]$, as well as tending to evaluate the value of the information they received even when it is delivered for advertising and marketing purposes $[28,68,83]$. Typically, satisfaction reflects the comparison results between one's expected and actual performance after experiencing the adopted product or service [81, 82]. If the actual performance equals or exceeds the expected performance, the consumers tend to be satisfied. The relationship between perceived value and satisfaction has been explored and studied in various contexts of B2B [82], B2C [90], online [15], and off-line businesses [53], however, it hasn't been tested in the proposed context of the gamified VRTWS. As we considered that the perceived value is very likely to positively influence satisfaction in the study, hypothesis H11 is postulated as:

H11: Perceived value positively influences satisfaction.

\subsection{Relationship between satisfaction and intention to adopt}

On the basis of prior literature, satisfaction is identified as being important in positively influencing users' intention of adopting specific products, services, new technology, or 


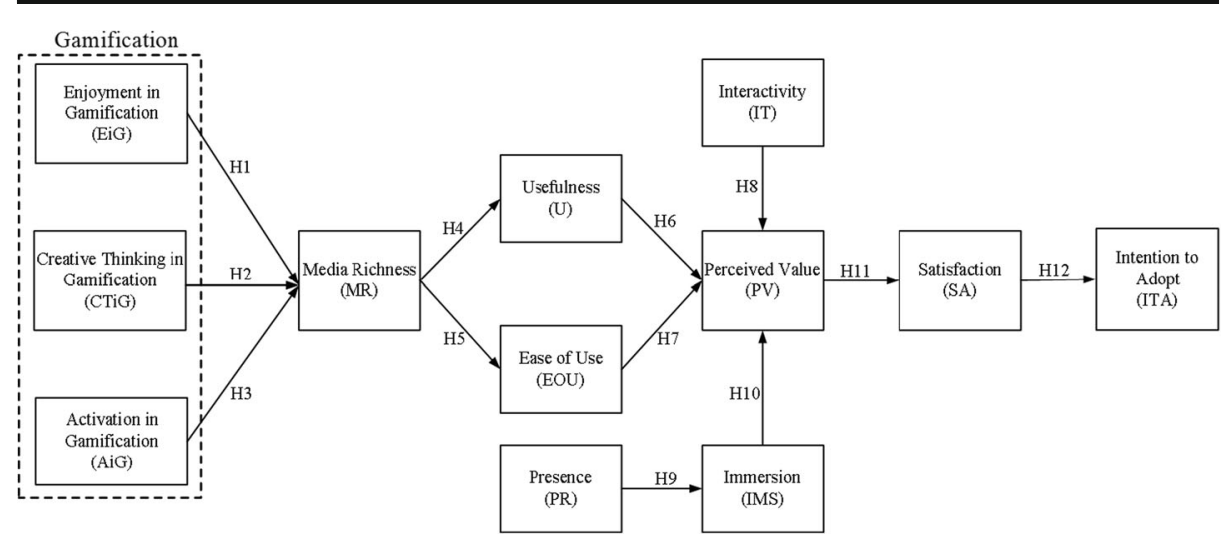

Fig. 1 The research framework of the study

innovative systems in various research contexts $[68,78,82,114]$. A consumer's higher level of satisfaction would lead to a higher intention of adopting, keep using, or re-purchasing the selected products/services $[19,53,68,82,114]$. In our study context, compared with ordinary tourism websites, the proposed gamified VRTWS is expected to provide a better experience with higher satisfaction, which is very likely to positively affect the intention of adoption. Consequently, hypothesis $\mathrm{H} 12$ is postulated as:

H12: Satisfaction positively influences intention to adopt.

\section{Research framework and the proposed gamified VR-enhanced tourism system}

\subsection{Research framework}

The study developed twelve hypotheses to form the research framework in investigating how gamification can influence consumer behavior in the proposed context of VRTWS. The research framework of the study is derived and illustrated in Fig. 1.

\subsection{The design and implementation of the proposed gamified VR-enhanced tourism system}

To test the proposed research framework, we first designed and developed a tourism ecommerce web system (with LazyDoor as the brand name) for positioning as a service providing tourism information as well as products and services on the Internet. Different from conventional online tourism websites (e.g., https:/en.liontravel.com/ ${ }^{1}$ ) that typically show pictures and itinerary information for tourism attractions, LazyDoor (see Fig. 2) provides an

\footnotetext{
${ }^{1}$ Lion Travel Co., LTD is one of the largest travel agencies providing tourism services both online (on https:// www.liontravel.com for both Chinese and English Version) and offline (in their 88 physical retailing stores in major cities in Taiwan and 14 physical retailing stores overseas). Its stock symbol in the Taiwan Stock Market is 2713.

Source: https://www.liontravel.com/retail/
} 

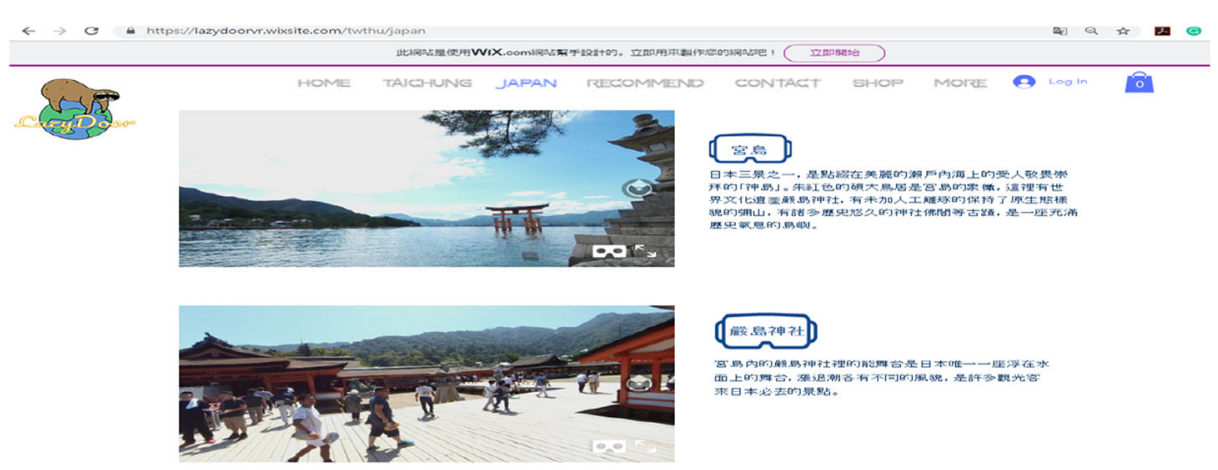

满查神社

8.

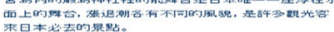

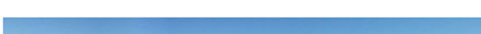

Fig. 2 The proposed VR-enhanced tourism web system (VRTWS): LazyDoor

embedded VR function and content that we established in advance by utilizing Unity [103], a real-time development software for creating 2D, 3D, VR, and AR visualizations for our tourism attractions. To further incorporate gamification in our VRTWS, we then utilized CoSpaces Edu to design games for constructing the proposed gamified VRTWS [22]. The rule-based gamification mechanism is designed to follow the principles: (1) users are allowed to experience free exploration in the scene, (2) tasks in the game are triggered when users move into certain area or contact specific characters, (3) tasks are designed to facilitate users' exploration in the scene (for example, Treasure Hunt requires users to find the listed items in a given period of time, and (4) tourism related information (e.g. history of the spot, ticket information, marketing messages, etc.) and scores are provided to the users immediately once a task is accomplished in the game. As shown in Fig. 3, our gamified VRTWS provides users both gameful and VR experience in the process of delivering marketing functions and messages for e-commerce in tourism. In addition, the selected Dali Art Plaza is an emerging hot sightseeing spot in Taiwan where the seated blue giant and big rose are all real on the buildings.

The architecture of the proposed gamified VRTWS is shown in Fig. 4. Users are allowed to interact with the system via web or mobile device based on his/her preference (however the study is conducted under the control that all participants use the VR headset and controller provided by us to maintain the consistency). For each tourism attraction, VR content/scene is created in advance and embedded into the proposed tourism web service of Lazydoor. Games are designed by using the third-party tool, CoSpaces Edu, for providing users gameful
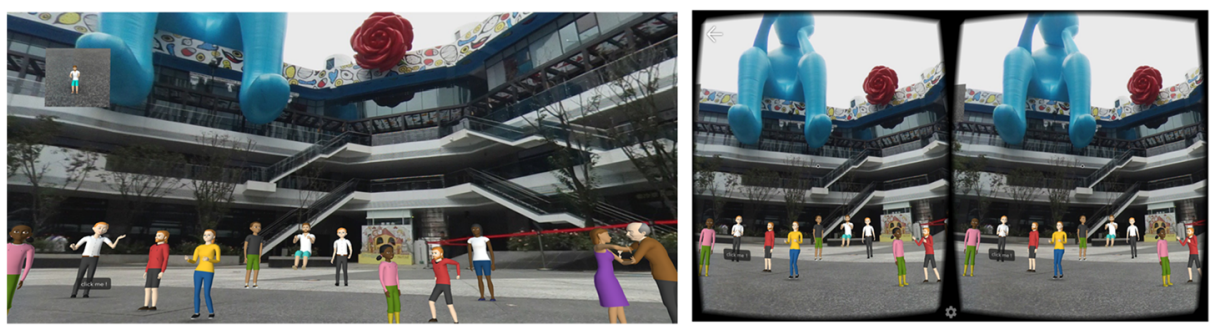

Fig. 3 Snapshot of our design of the proposed gamified VRTWS and its VR user experience mode for tourism attraction: Dali Art Plaza in Taichung Software Park, Taiwan 


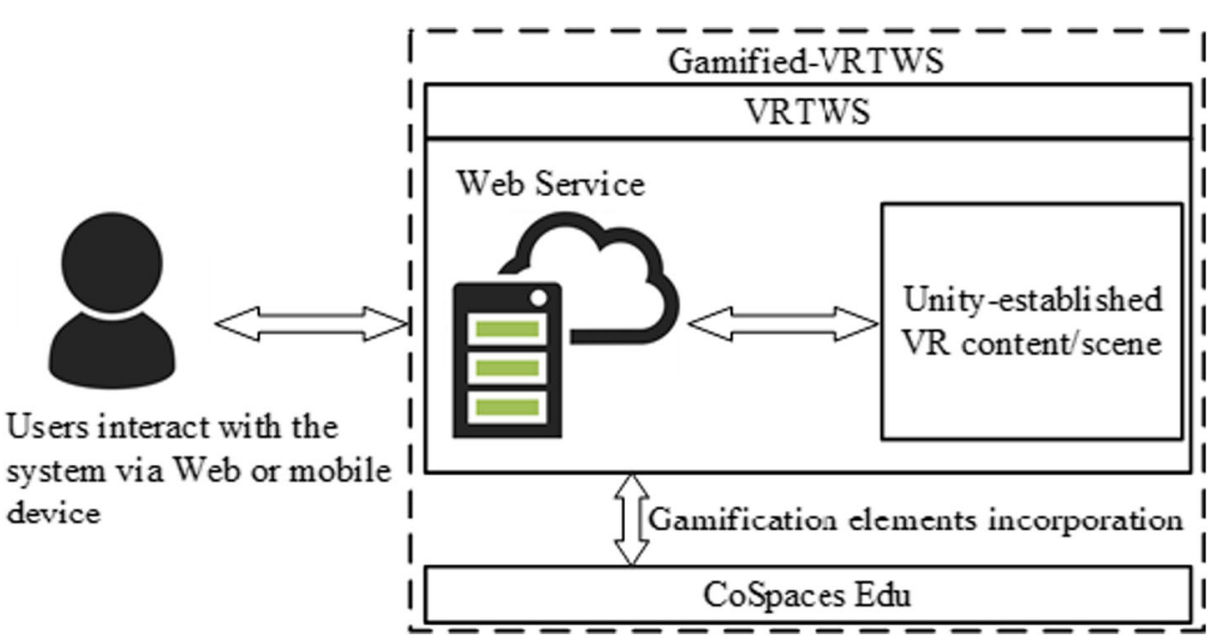

Fig. 4 Architecture of the proposed gamified VRTWS

experience. In addition, the proposed gamified VRTWS combines the system design philosophy of three levels of information and services:

- Level I: Tourism Web System (TWS) provides conventional information and services for tourism products.

- Level II: VR-enhanced Tourism Web System (VRTWS) provides VR feature (without gameful experience) plus conventional information and services for tourism products.

- Level III: Gamified VRTWS further provides gameful experience based on the foundation of VRTWS.

In the study, the tested hypotheses and validated research framework focus on Level III scenario, in which gamification and virtual reality (VR)-enhanced web services are integrated for the investigation.

\section{Empirical analysis and results}

\subsection{Questionnaire development}

In the study, in order to ensure content validity, the questionnaire items (observed indicators) of the research framework were adapted from literature review. A 5-point Likert scale, ranging from strongly disagree (1) to strongly agree (5), was used to measure questionnaire items of each dimension (latent variable) in the proposed research framework. Before formal survey, a pretest in a small group was conducted in advance to make sure the questionnaires could be clearly understood and validly measured. According to the feedbacks and results from the pretest, modifications on the questionnaire items were then made for improving reliability for formal survey. 


\subsection{Analytical methodology: PLS-SEM analysis}

This study adopted PLS-structural equation modeling (PLS-SEM) approach to analyze the collected data and test the proposed research framework [39, 41]. PLS-SEM has been recognized as a powerful multivariate analysis technique as well as path modeling tool for empirical data analyses as it can be used for modeling latent constructs with minimum restrictions even under the condition of small sample size and non-normality [17, 40, 101]. SmartPLS 3.0, a PLS-SEM analytical software, was used to test the outer model as well as the inner model of the research framework for the collected data. In PLS-SEM, the outer model (also called the measurement model) specifies the relationships between the manifest variables and the latent variables; while the inner model (also known as the structural model) indicates the relationships between the latent variables of the proposed research framework. In addition, uni-dimensionality checks for all constructs were carried out before conducting the outer model (measurement model) tests and inner model (structural model) tests in the study [39, 41]. The following sections elaborate the procedure and analytical results of the data collection, descriptive analyses, and PLS-SEM statistics.

\subsection{Data collection and descriptive statistics}

According to a Greenlight Insights report, the survey's virtual reality statistics show that $55 \%$ of Generation Z (born 1997-2005) respondents who say they are familiar with VR have also tried it [50]. In addition, $43 \%$ of Generation $\mathrm{Z}$ use OTAs (Online Travel Agents) to plan trips and take an average of 29 days per year [31]. Therefore, customers who are those potential tourists accept the delivered marketing information by a gamified VR-enhanced tourism web system (VRTWS) are definitely skewed toward the younger generations. Therefore, the empirical data of the study were collected mainly at the Tunghai University campus in Taiwan. On the basis of convenience sampling, participants were invited to join the test of experiencing the gamified VRTWS. The participants who accepted our test invitation were then led to our test site (a place with our experiment equipment all set) based on the schedule arrangement. Before each test started, our research team members gave the participants a brief introduction to using the VR headset and controlling the movements in the VRTWS (see Fig. 5). The designed gamified tasks in the VRTWS were also described. For example, the participants can find "Wally" (the virtual characters based on the story of "Where's Wally?") by operating the remote controller to get points, and contacting and clicking on other people to get more information about this scenery (Dali Art Plaza in Taichung Software Park) in our designed gamified tasks.
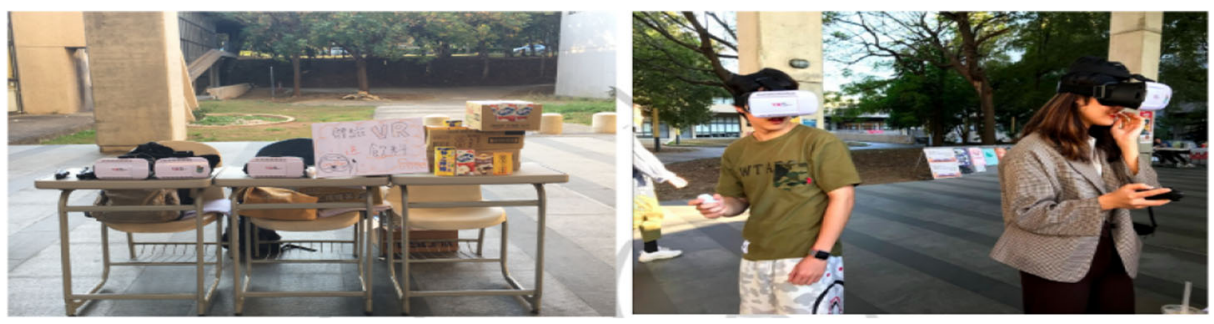

Fig. 5 Snapshot of the user experience in the proposed gamified VRTWS 
For each participant, he or she was asked to fill in the research questionnaires immediately after experiencing the gamified VRTWS. The test time for each participant was around $30 \mathrm{~min}$ in average. In total, 234 samples were gathered. Among 234 empirical samples, a few were discarded as they were identified as incomplete and invalid. Overall, 208 usable samples were retained and used for analysis. Of the 208 usable respondents, males were $76(36.6 \%)$ while females were $132(63.4 \%)$. Because of the nature of convenience sampling at the management college of our university, the female percentage is a little higher than that for males. It is important to retain as many participants as possible. In the study, except for one item (U1), there is no statistically significant difference (with a confidence level of 0.95 ) found in all t-tests on two groups (male and female) for all questionnaire items. As the $p$ value of the exception item (U1) is 0.032 , which is very close to 0.05 with a significance level of one star $\left(^{*}\right)$, it was decided to retain the exception item (U1) in the subsequent analyses for keeping as many items as possible in preserving the integrity of the analysis [6]. In terms of age, 150 (72\%) were in the 15-20 years age group, 51 (24.5\%) were in the 21-30 years age group, and the remaining $7(3.5 \%)$ were 31 years old or older. Therefore, the main participants represent the potential tourists who are those Generation $\mathrm{Z}$ accept the delivered marketing information by a gamified VR-enhanced tourism web system (VRTWS).

As for educational background, 192 (92.3\%) participants were college level, whereas 16 (7.7\%) were at the postgraduate level. Two hundred and eight (100\%) participants have the experience in looking up for tourism information on the Internet for at least 3 years. None of the participants have used VR technology to access online tourism services. For the yearly traveling budget, 39 (18.8\%) participants have a yearly budget of less than NT\$10,000, 131 (63\%) participants have a yearly budget between NT\$10,000 and NT\$39,999, 26 (12.5\%) participants have a yearly budget between NT\$40,000 and NT\$59,999, 7 (3.4\%) participants have a yearly budget between NT\$60,000 and NT\$99,999 group, and the remaining $5(2.3 \%)$ participants have a yearly budget of more than NT $\$ 100,000$. Table 1 lists the descriptive statistics of the surveyed questionnaire items and factors in the proposed research framework as well as their literature sources.

\subsection{Test for Uni-dimensionality of all blocks}

To check the uni-dimensionality of a block, there are three available tools and indicators: (1) principal component analysis of a block, (2) composite reliability (CR), and (3) Cronbach's alpha $(\alpha)$ [101]. From the statistics in principal component analysis, if the first eigenvalue in the correlation matrix of a block is larger than 1 and the second eigenvalue is less than 1 (or at least very far away from the first one), then the block of manifest variables is identified as unidimensional. In addition, when $C R$ value and Cronbach's alpha value are greater than 0.7 , the block can also be considered as unidimensional [39, 41]. In the study (shown in Table 2), the first eigenvalues of all ten blocks in principal component analysis are larger than 1 and the second eigenvalues of all ten blocks are less than 1, and the statistics (ranging from 0.905 to 0.979 in CR value and 0.823 to 0.967 in Cronbach's alpha $(\alpha)$ ) in uni-dimensionality tests all exceeded the threshold of 0.7 , thus concluding the uni-dimensionality was supported by all three aforementioned tools. 
Table 1 Descriptive statistics of measurement scales

\begin{tabular}{|c|c|c|c|c|c|}
\hline Factor & Item & Concept & Mean & S.D. & $\begin{array}{l}\text { Source/ } \\
\text { Adapted } \\
\text { from }\end{array}$ \\
\hline \multirow{4}{*}{$\begin{array}{l}\text { Enjoyment in } \\
\text { Gamification } \\
\text { (EiG) }\end{array}$} & $\cdot$ EiG1 & The games in VR are interesting. & 3.94 & 0.904 & \multirow[t]{4}{*}[30]{} \\
\hline & $\cdot$ EiG2 & I like to play the games in VR. & 3.88 & 0.948 & \\
\hline & $\cdot$ EiG3 & I enjoy playing the games in VR. & 3.93 & 0.935 & \\
\hline & $\cdot$ EiG4 & Playing the games in VR is pleasurable. & 4.05 & 0.902 & \\
\hline \multirow{3}{*}{$\begin{array}{l}\text { Creative Thinking in } \\
\text { Gamification } \\
\text { (CTiG) }\end{array}$} & $\cdot$ CTiG1 & Playing the games in VR inspires my imagination. & 3.92 & 0.914 & \multirow[t]{3}{*}[30]{} \\
\hline & $\cdot$ CTiG2 & $\begin{array}{l}\text { I felt like I could explore new things when I was } \\
\text { playing the games in VR. }\end{array}$ & 4.16 & 0.853 & \\
\hline & $\cdot$ CTiG3 & $\begin{array}{l}\text { I felt like I was on an adventure when I was playing } \\
\text { the games in VR. }\end{array}$ & 4.11 & 0.944 & \\
\hline \multirow{2}{*}{$\begin{array}{l}\text { Activation in } \\
\text { Gamification } \\
\text { (AiG) }\end{array}$} & $\cdot$ AiG1 & I felt active when I was playing the games in VR. & 4.02 & 0.890 & \multirow[t]{2}{*}[30]{} \\
\hline & $\cdot \mathrm{AiG} 2$ & I felt excited when I was playing the games in VR. & 4.06 & 0.835 & \\
\hline \multirow{4}{*}{$\begin{array}{l}\text { Media Richness } \\
\quad(\mathrm{MR})\end{array}$} & $\cdot$ MR1 & I feel that VR provides the information that I need. & 3.95 & 0.829 & \multirow[t]{4}{*}[12,26]{} \\
\hline & $\cdot \mathrm{MR} 2$ & I feel that I can get instant feedback by using VR. & 3.96 & 0.886 & \\
\hline & $\cdot \mathrm{MR} 3$ & I feel VR could provide me multiple clues. & 4.09 & 0.869 & \\
\hline & $\cdot$ MR4 & $\begin{array}{l}\text { I feel that the information is presented in a more } \\
\text { natural way via VR. }\end{array}$ & 3.89 & 0.972 & \\
\hline \multirow[t]{3}{*}{ Usefulness (U) } & $\cdot \mathrm{U} 1$ & $\begin{array}{l}\text { The adoption of VR technology in tourism } \\
\text { guidance is considered helpful. }\end{array}$ & 4.32 & 0.772 & \multirow[t]{3}{*}[25]{} \\
\hline & $\cdot \mathrm{U} 2$ & $\begin{array}{l}\text { VR technology allows me to get more information } \\
\text { about the tourism destination. }\end{array}$ & 4.31 & 0.738 & \\
\hline & $\cdot \mathrm{U} 3$ & I feel VR is useful. & 4.10 & 0.859 & \\
\hline \multirow[t]{3}{*}{ Ease of Use (EOU) } & $\cdot$ EOU1 & It doesn't take too much effort to use VR. & 3.96 & 0.997 & \multirow[t]{3}{*}[25,56]{} \\
\hline & $\cdot$ EOU2 & The interaction with VR is clear and easy. & 4.14 & 0.813 & \\
\hline & $\cdot$ EOU3 & I feel VR is easy to use. & 4.16 & 0.847 & \\
\hline \multirow[t]{3}{*}{$\begin{array}{l}\text { Perceived Value } \\
\qquad(\mathrm{PV})\end{array}$} & $\cdot$ PV1 & $\begin{array}{l}\text { I feel that it is worthwhile to spend the time to } \\
\text { experience the tourism destination through VR. }\end{array}$ & 4.25 & 0.765 & \multirow[t]{3}{*}[100,113]{} \\
\hline & $\cdot$ PV2 & $\begin{array}{l}\text { I feel that it is worthwhile to make the mental effort } \\
\text { to experience the tourism destination through } \\
\text { VR. }\end{array}$ & 4.25 & 0.814 & \\
\hline & $\cdot \mathrm{PV} 3$ & $\begin{array}{l}\text { I feel that it is worthwhile to make the physical } \\
\text { effort to experience the tourism destination } \\
\text { through VR. }\end{array}$ & 4.19 & 0.839 & \\
\hline \multirow[t]{2}{*}{ Interactivity (IT) } & $\cdot$ IT1 & $\begin{array}{l}\text { I feel that the adoption of VR could help me } \\
\text { achieve two-way interaction with the system. }\end{array}$ & 4.14 & 0.843 & \multirow[t]{2}{*}[66]{} \\
\hline & $\cdot$ IT2 & $\begin{array}{l}\text { I feel VR could let me control the information that I } \\
\text { want to know. }\end{array}$ & 4.08 & 0.878 & \\
\hline \multirow[t]{4}{*}{ Presence (PR) } & $\cdot$ PR1 & $\begin{array}{l}\text { The objects or characters that I saw in VR made me } \\
\text { feel like I was in that place. }\end{array}$ & 3.97 & 0.865 & \multirow[t]{4}{*}[64,107]{} \\
\hline & $\cdot$ PR2 & $\begin{array}{l}\text { It felt like I was able to reach out and touch the } \\
\text { objects or characters that I saw in VR. }\end{array}$ & 3.78 & 1.012 & \\
\hline & $\cdot$ PR3 & $\begin{array}{l}\text { I have a feeling of being in the environment that I } \\
\text { saw in VR. }\end{array}$ & 4.01 & 0.901 & \\
\hline & $\cdot$ PR4 & I want to try to touch what I saw in VR. & 3.75 & 1.027 & \\
\hline \multirow[t]{4}{*}{ Immersion (IMS) } & $\cdot$ IMS1 & The VR context has largely caught my attention. & 4.26 & 0.800 & \multirow[t]{4}{*}[55]{} \\
\hline & $\cdot$ IMS2 & I was very focused in the VR context. & 4.19 & 0.850 & \\
\hline & $\cdot \mathrm{IMS} 3$ & When using the VR, I felt that time passed faster. & 3.73 & 1.088 & \\
\hline & $\cdot$ IMS4 & $\begin{array}{l}\text { When using the VR, I felt that I was at the tourism } \\
\text { destination. }\end{array}$ & 3.94 & 0.969 & \\
\hline \multirow[t]{2}{*}{ Satisfaction (SA) } & $\cdot$ SA1 & $\begin{array}{l}\text { Compared with the expected situation, I am } \\
\text { satisfied with the VR experience. }\end{array}$ & 4.15 & 0.826 & \multirow[t]{2}{*}[82]{} \\
\hline & $\cdot \mathrm{SA} 2$ & $\begin{array}{l}\text { Compared with the expected situation, I am } \\
\text { satisfied with using VR in tourism guidance. }\end{array}$ & 4.11 & 0.845 & \\
\hline
\end{tabular}
satisfied with using VR in tourism guidance. 
Table 1 (continued)

\begin{tabular}{|c|c|c|c|c|c|}
\hline Factor & Item & Concept & Mean & S.D. & $\begin{array}{l}\text { Source/ } \\
\text { Adapted } \\
\text { from }\end{array}$ \\
\hline \multirow{6}{*}{$\begin{array}{l}\text { Intention to Adopt } \\
\text { (ITA) }\end{array}$} & $\cdot$ SA3 & $\begin{array}{l}\text { Overall, I am satisfied with the VR experience of } \\
\text { this time. }\end{array}$ & 4.25 & 0.782 & \multirow{6}{*}[86,110]{} \\
\hline & $\cdot$ SA4 & $\begin{array}{l}\text { Compared with the expected situation, I am } \\
\text { satisfied with the tourism information provided } \\
\text { by VR. }\end{array}$ & 4.11 & 0.845 & \\
\hline & $\cdot$ ITA1 & $\begin{array}{l}\text { I am willing to go to visit the tourism destination } \\
\text { presented in VR. }\end{array}$ & 4.04 & 0.918 & \\
\hline & $\cdot$ ITA2 & $\begin{array}{l}\text { I am willing to recommend the tourism destination } \\
\text { which is presented in VR to my friends. }\end{array}$ & 3.80 & 0.975 & \\
\hline & $\cdot$ ITA3 & $\begin{array}{l}\text { I have a high willingness to go to visit the tourism } \\
\text { destination presented in VR. }\end{array}$ & 3.79 & 1.045 & \\
\hline & $\cdot$ ITA4 & $\begin{array}{l}\text { Overall, it is highly possible for me to visit the } \\
\text { tourism destination presented in VR. }\end{array}$ & 3.95 & 0.916 & \\
\hline
\end{tabular}

\subsection{Test of the outer model (measurement model)}

The outer model (also known as measurement model) estimation results together with the outer loadings and the average variance extracted (AVE) measures, are shown in Table 2. In PLS-SEM analysis, the outer loadings represent the loading values of the reflective manifest variables to their respective latent variable, and it can be used to assess the reliability of individual item. Suggested by prior studies [40,89], when a loading value is larger than 0.7 , the individual item reliability is considered as acceptable. In the study, all outer loadings are found larger than the suggested standard of 0.7. Based on prior study [32], the convergent validity of a reflective construct can be assessed by AVE measures with a threshold of 0.5. In our study (as shown in Table 2), all AVE scores (ranging from 0.709 to 0.940 ) exceeded the suggested standard of 0.5 , concluding the convergent validity was supported by the results. Also, suggested by Fornell and Larcker [32], the discriminant validity of the constructs in the model can be assessed by checking the square root of the AVE measure of each construct and see if it is larger than the estimated correlations shared between the construct and other constructs in the model. The analytical results (shown in Table 3) revealed that the discriminant validity of the constructs was acceptable as the square root of the AVE measure of each construct was larger than the correlations of the construct with other constructs. Moreover, the matrix of loadings and cross-loadings for all reflective items can also be used as additional evidence in assessing the convergent validity and discriminant validity of the constructs by checking whether each cross-loading difference is higher than the suggested threshold of $0.1[35,47]$. The convergent validity and discriminant validity of the study was concluded to be supported by Table 4 .

\subsection{Inner model (structural model) results}

In PLS-SEM analysis, the inner model (also known as structural model) specifies the relationships between latent variables. The inner model results together with the estimated path coefficients for the endogenous latent variables and R-square statistics are illustrated in Fig. 6 and Table 5 . 
Table 2 Block uni-dimensionality checks, loadings, and average variance extracted $(n=208)$

\begin{tabular}{|c|c|c|c|c|c|c|c|}
\hline Latent variable & $\begin{array}{l}\text { Manifest } \\
\text { variable }\end{array}$ & Loadings & $\begin{array}{l}\text { First } \\
\text { eigenvalue }\end{array}$ & $\begin{array}{l}\text { Second } \\
\text { eigenvalue }\end{array}$ & $\begin{array}{l}\text { Composite } \\
\text { Reliability } \\
\text { (CR) }\end{array}$ & $\begin{array}{l}\text { Cronbach's } \\
\alpha\end{array}$ & AVE \\
\hline $\begin{array}{l}\text { Enjoyment in } \\
\text { Gamification (EiG) }\end{array}$ & $\begin{array}{l}\cdot \text { EiG1 } \\
\cdot \text { EiG2 } \\
\cdot \text { EiG3 } \\
\cdot \text { EiG4 }\end{array}$ & $\begin{array}{l}0.910 \\
0.948 \\
0.946 \\
0.926\end{array}$ & 3.480 & 0.249 & 0.964 & 0.950 & 0.870 \\
\hline $\begin{array}{l}\text { Creative Thinking in } \\
\text { Gamification (CTiG) }\end{array}$ & $\begin{array}{l}\cdot \text { CTiG1 } \\
\cdot \text { CTiG2 } \\
\cdot \text { CTiG3 }\end{array}$ & $\begin{array}{l}0.882 \\
0.942 \\
0.908\end{array}$ & 2.490 & 0.356 & 0.936 & 0.895 & 0.830 \\
\hline $\begin{array}{l}\text { Activation in } \\
\text { Gamification (AiG) }\end{array}$ & $\begin{array}{l}\cdot \text { AiG1 } \\
\cdot \text { AiG2 }\end{array}$ & $\begin{array}{l}0.915 \\
0.929\end{array}$ & 1.701 & 0.299 & 0.919 & 0.823 & 0.850 \\
\hline Media Richness (MR) & $\begin{array}{l}\cdot \mathrm{MR} 1 \\
\cdot \mathrm{MR} 2 \\
\cdot \mathrm{MR} 3 \\
\cdot \mathrm{MR} 4\end{array}$ & $\begin{array}{l}0.835 \\
0.851 \\
0.891 \\
0.824\end{array}$ & 2.896 & 0.438 & 0.913 & 0.871 & 0.724 \\
\hline Usefulness (U) & $\begin{array}{l}\cdot \mathrm{U} 1 \\
\cdot \mathrm{U} 2 \\
\cdot \mathrm{U} 3\end{array}$ & $\begin{array}{l}0.879 \\
0.896 \\
0.860\end{array}$ & 2.316 & 0.416 & 0.910 & 0.848 & 0.771 \\
\hline Ease of Use (EOU) & $\begin{array}{l}\cdot \text { EOU1 } \\
\cdot \text { EOU2 } \\
\cdot \text { EOU3 }\end{array}$ & $\begin{array}{l}0.790 \\
0.895 \\
0.925\end{array}$ & 2.282 & 0.507 & 0.905 & 0.832 & 0.760 \\
\hline Perceived Value (PV) & $\begin{array}{l}\cdot \text { PV1 } \\
\cdot \text { PV2 } \\
\cdot \text { PV3 }\end{array}$ & $\begin{array}{l}0.969 \\
0.977 \\
0.963\end{array}$ & 2.820 & 0.110 & 0.979 & 0.967 & 0.940 \\
\hline Interactivity (IT) & $\begin{array}{l}\cdot \text { IT1 } \\
\cdot \text { IT2 }\end{array}$ & $\begin{array}{l}0.929 \\
0.930\end{array}$ & 1.729 & 0.271 & 0.927 & 0.843 & 0.864 \\
\hline Presence (PR) & $\begin{array}{l}\cdot \text { PR1 } \\
\cdot \text { PR2 } \\
\cdot \text { PR3 } \\
\cdot \text { PR4 }\end{array}$ & $\begin{array}{l}0.854 \\
0.895 \\
0.918 \\
0.849\end{array}$ & 3.095 & 0.407 & 0.932 & 0.900 & 0.773 \\
\hline Immersion (IMS) & $\begin{array}{l}\cdot \text { IMS1 } \\
\cdot \text { IMS2 } \\
\cdot \text { IMS3 } \\
\cdot \text { IMS4 }\end{array}$ & $\begin{array}{l}0.892 \\
0.859 \\
0.735 \\
0.872\end{array}$ & 2.835 & 0.634 & 0.906 & 0.851 & 0.709 \\
\hline Satisfaction (SA) & $\begin{array}{l}\cdot \text { SA1 } \\
\cdot \text { SA2 } \\
\cdot \text { SA3 } \\
\cdot \text { SA4 }\end{array}$ & $\begin{array}{l}0.914 \\
0.931 \\
0.861 \\
0.879\end{array}$ & 3.215 & 0.379 & 0.942 & 0.918 & 0.804 \\
\hline Intention to Adopt (ITA) & $\begin{array}{l}\cdot \text { ITA1 } \\
\cdot \text { ITA2 } \\
\cdot \text { ITA3 } \\
\cdot \text { ITA4 }\end{array}$ & $\begin{array}{l}0.928 \\
0.921 \\
0.937 \\
0.935\end{array}$ & 3.460 & 0.225 & 0.962 & 0.947 & 0.865 \\
\hline
\end{tabular}

$E i G$, Enjoyment in Gamification; $C T i G$, Creative Thinking in Gamification; $A i G$, Activation in Gamification; $M R$, Media Richness; $U$, Usefulness; $E O U$, Ease of Use; $P V$, Perceived Value; $I T$, Interactivity; $P R$, Presence; IMS, Immersion; SA, Satisfaction; ITA, Intention to Adopt

The empirical results (Fig. 6 and Table 5) reveal that both Enjoyment in Gamification ( $\beta=$ $\left.0.357^{* * *}, p<0.001\right)$ and Activation in Gamification $\left(\beta=0.216^{*}, p=0.046\right)$ significantly and positively affect Media Richness. However, Creative Thinking in Gamification $(\beta=0.180, p=$ 0.067 ) is not significantly associated with Media Richness. In addition, Media Richness was found to significantly and positively affect both Usefulness $(\beta=0.701 * * *, p<0.001)$ and Ease of Use $\left(\beta=0.489^{* * *}, p<0.001\right)$ in using VR technology with gamification element for marketing in tourism e-commerce. Furthermore, users' Perceived Value is significantly and 
Table 3 Inter-construct correlations and square root of AVE measure of twelve constructs

\begin{tabular}{|c|c|c|c|c|c|c|c|c|c|c|c|c|}
\hline & $\mathrm{EiG}$ & CTiG & $\mathrm{AiG}$ & MR & $\mathrm{U}$ & EOU & PV & IT & PR & IMS & SA & ITA \\
\hline $\mathrm{EiG}$ & 0.933 & & & & & & & & & & & \\
\hline CTiG & 0.660 & 0.911 & & & & & & & & & & \\
\hline $\mathrm{AiG}$ & 0.737 & 0.823 & 0.922 & & & & & & & & & \\
\hline MR & 0.635 & 0.593 & 0.627 & 0.851 & & & & & & & & \\
\hline $\mathrm{U}$ & 0.542 & 0.497 & 0.502 & 0.701 & 0.878 & & & & & & & \\
\hline EOU & 0.451 & 0.402 & 0.361 & 0.489 & 0.575 & 0.872 & & & & & & \\
\hline PV & 0.576 & 0.540 & 0.537 & 0.716 & 0.669 & 0.622 & 0.970 & & & & & \\
\hline IT & 0.553 & 0.561 & 0.538 & 0.741 & 0.660 & 0.543 & 0.672 & 0.930 & & & & \\
\hline PR & 0.547 & 0.587 & 0.568 & 0.675 & 0.543 & 0.474 & 0.639 & 0.591 & 0.879 & & & \\
\hline IMS & 0.599 & 0.652 & 0.633 & 0.729 & 0.636 & 0.544 & 0.712 & 0.657 & 0.847 & 0.842 & & \\
\hline SA & 0.662 & 0.628 & 0.654 & 0.755 & 0.692 & 0.632 & 0.860 & 0.761 & 0.860 & 0.788 & 0.897 & \\
\hline ITA & 0.613 & 0.611 & 0.602 & 0.684 & 0.548 & 0.464 & 0.663 & 0.602 & 0.616 & 0.631 & 0.761 & 0.930 \\
\hline
\end{tabular}

$E i G$, Enjoyment in Gamification; $C T i G$, Creative Thinking in Gamification; $A i G$, Activation in Gamification; $M R$, Media Richness; $U$, Usefulness; $E O U$, Ease of Use; $P V$, Perceived Value; $I T$, Interactivity; $P R$, Presence; $I M S$, Immersion; SA, Satisfaction; ITA, Intention to Adopt

positively affected by not only Usefulness $\left(\beta=0.198^{* *}, p=0.009\right)$ and Ease of Use $(\beta=$ $\left.0.216^{* * *}, p<0.001\right)$ in using VR but also the constructs of Interactivity $(\beta=0.203 * *, p=$ $0.006)$ and Immersion $\left(\beta=0.335^{* * *}, p<0.001\right)$ in the study. Presence is found to have a significant and positive effect on Immersion $\left(\beta=0.847^{* * *}, p<0.001\right)$. Moreover, users' Perceived Value also significantly and positively affects their perceived Satisfaction $(\beta=$ $\left.0.860^{* * *}, p<0.001\right)$. Last but not least, users' Satisfaction would significantly and positively affect their intention of adoption $\left(\beta=0.761^{* * *}, p<0.001\right)$. Overall, the hypotheses (H1 and $\mathrm{H} 3$ to H12) were found to be supported by the empirical results, while the hypothesis (H2) was not supported in the study.

\section{Discussion}

Responding to the need of better understanding how gamification and VR-enhanced web services can be integrated to influence consumer behavior in tourism e-commerce context, this study designed and implemented a gamified VRTWS, proposed a research framework with 12 postulated hypotheses, collected empirical data from 208 participants, and adopted PLS-SEM approach to analyze the research data and validate the framework. Several findings are revealed by our empirical study results to show that VR could contribute the tourism industry under the likely long-term effects of the COVID-19 pandemic.

First, both enjoyment in gamification and activation in gamification are found to have significant and positive impact on media richness. These results suggest both enjoyment and activation elements in gamification would contribute to the increase of media richness for the delivered information. In other words, by providing users an enjoyable and activated experience in the gamified VRTWS, the degree of the ability in enabling users in communication is increased. In addition, enjoyment, with a larger path coefficient $(0.357 * * *)$, has a stronger effect on media richness than activation $\left(0.216^{*}\right)$. Creating an enjoyable user experience may be considered the priority in such a context compared with activating the users in increasing media richness levels. 
Table 4 Matrix of loadings and cross-loadings of twelve constructs

\begin{tabular}{|c|c|c|c|c|c|c|c|c|c|c|c|c|c|}
\hline Latent variable & Item & $\mathrm{EiG}$ & CTiG & $\mathrm{AiG}$ & MR & $\mathrm{U}$ & EOU & PV & IT & PR & IMS & SA & ITA \\
\hline \multirow{4}{*}{$\begin{array}{l}\text { Enjoyment in } \\
\text { Gamification (EiG) }\end{array}$} & · EiG1 & .910 & .549 & .647 & .597 & .497 & .443 & .520 & .516 & .518 & .545 & .600 & .537 \\
\hline & $\cdot$ EiG2 & .948 & .625 & .689 & .587 & .503 & .408 & .536 & .533 & .491 & .537 & .622 & .583 \\
\hline & $\cdot$ EiG3 & .946 & .655 & .705 & .583 & .499 & .402 & .523 & .522 & .474 & .552 & .613 & .572 \\
\hline & $\cdot$ EiG4 & .926 & .633 & .708 & .599 & .523 & .428 & .571 & .493 & .557 & .600 & .632 & .594 \\
\hline \multirow{3}{*}{$\begin{array}{l}\text { Creative Thinking in } \\
\text { Gamification } \\
\text { (CTiG) }\end{array}$} & - CTiG1 & .597 & .882 & .693 & .552 & .411 & .369 & .453 & .523 & .531 & .585 & .524 & .552 \\
\hline & - CTiG2 & .589 & .942 & .765 & .531 & .472 & .375 & .501 & .511 & .554 & .599 & .583 & .527 \\
\hline & - CTiG3 & .616 & .908 & .790 & .536 & .476 & .353 & .521 & .498 & .519 & .598 & .610 & .590 \\
\hline \multirow{2}{*}{$\begin{array}{l}\text { Activation in } \\
\text { Gamification (AiG) }\end{array}$} & $\cdot \mathrm{AiG} 1$ & .640 & .788 & .915 & .551 & .483 & .326 & .474 & .522 & .516 & .574 & .601 & .552 \\
\hline & $\cdot \mathrm{AiG} 2$ & .716 & .732 & .929 & .604 & .446 & .339 & .514 & .474 & .531 & .592 & .605 & .558 \\
\hline \multirow[t]{4}{*}{ Media Richness (MR) } & $\cdot$ MR1 & .496 & .471 & .516 & .835 & .604 & .405 & .554 & .692 & .535 & .527 & .630 & .568 \\
\hline & $\cdot$ MR2 & .522 & .501 & .555 & .851 & .519 & .354 & .582 & .626 & .526 & .603 & .584 & .564 \\
\hline & $\cdot \mathrm{MR} 3$ & .613 & .548 & .599 & .891 & .667 & .437 & .642 & .645 & .592 & .674 & .699 & .561 \\
\hline & $\cdot$ MR4 & .520 & .494 & .458 & .824 & .584 & .460 & .653 & .558 & .641 & .669 & .649 & .638 \\
\hline \multirow[t]{3}{*}{ Usefulness (U) } & $\cdot \mathrm{U} 1$ & .457 & & & & & .481 & .549 & .533 & .477 & .529 & 33 & .505 \\
\hline & $\cdot \mathrm{U} 2$ & .514 & .478 & .507 & .649 & .896 & .450 & .547 & .596 & .477 & .573 & .588 & .457 \\
\hline & $\cdot \mathrm{U} 3$ & .456 & .439 & .420 & .610 & .860 & .578 & .661 & .606 & .476 & .569 & .648 & .483 \\
\hline \multirow[t]{3}{*}{ Ease of Use (EOU) } & $\cdot$ EOU1 & .344 & .263 & .229 & .314 & .449 & .790 & .506 & .342 & .359 & .423 & .476 & .334 \\
\hline & - EOU2 & .405 & .388 & .365 & .497 & .532 & .895 & .530 & .558 & .423 & .462 & .570 & .434 \\
\hline & $\cdot$ EOU3 & .426 & .387 & .338 & .451 & .520 & .925 & .590 & .501 & .453 & .532 & .598 & .438 \\
\hline \multirow[t]{3}{*}{ Perceived Value (PV) } & $\cdot$ PV1 & .572 & .557 & .543 & .703 & .663 & .585 & .969 & 677 & .633 & .700 & .854 & .677 \\
\hline & & .575 & & & & & & & & .621 & & 50 & .637 \\
\hline & $\cdot$ PV3 & .528 & .490 & .477 & .684 & .625 & .606 & .963 & .631 & .603 & .665 & .794 & .615 \\
\hline \multirow[t]{2}{*}{ Interactivity (IT) } & $\cdot$ IT1 & .449 & .489 & .441 & .643 & .622 & .497 & .622 & .929 & .551 & .583 & .658 & .519 \\
\hline & $\cdot$ IT2 & .579 & .555 & .560 & .734 & .606 & .512 & .627 & .930 & .548 & .639 & .699 & .600 \\
\hline \multirow[t]{4}{*}{ Presence (PR) } & $\cdot$ PR1 & .442 & .470 & .467 & .618 & .527 & .441 & .613 & .588 & .854 & .759 & .685 & .575 \\
\hline & $\cdot$ PR2 & .466 & .467 & .450 & .583 & .475 & .391 & .541 & .500 & .895 & .687 & .580 & .512 \\
\hline & $\cdot$ PR3 & .536 & .565 & .550 & .649 & .520 & .450 & .607 & .524 & .918 & .826 & .683 & .555 \\
\hline & $\cdot$ PR4 & .475 & .559 & .527 & .515 & .376 & .380 & & .459 & 49 & .692 & .567 & .521 \\
\hline \multirow[t]{4}{*}{ Immersion (IMS) } & $\cdot$ IMS1 & .556 & .625 & 619 & .692 & .592 & .521 & .685 & .641 & .753 & .892 & .749 & .607 \\
\hline & $\cdot$ IMS2 & .485 & .535 & .528 & .684 & .579 & .513 & .629 & .626 & .711 & .859 & .689 & .510 \\
\hline & $\cdot$ IMS3 & .441 & .470 & .441 & .430 & .423 & .344 & .467 & .403 & .603 & .735 & .529 & .461 \\
\hline & $\cdot$ IMS4 & .528 & .557 & .527 & .617 & .531 & .436 & .597 & .520 & .773 & .872 & .668 & .539 \\
\hline \multirow[t]{4}{*}{ Satisfaction (SA) } & $\cdot$ SA1 & .623 & .532 & .568 & .674 & .607 & .595 & .760 & .669 & .660 & .733 & .914 & .665 \\
\hline & $\cdot \mathrm{SA} 2$ & .578 & .574 & .579 & .692 & .642 & .607 & .777 & .647 & .673 & .733 & .931 & .700 \\
\hline & - SA3 & 670 & .619 & 677 & .673 & .584 & .494 & .695 & .657 & .599 & .673 & .861 & .726 \\
\hline & $\cdot$ SA4 & .506 & .528 & .524 & .668 & .645 & .566 & .845 & .644 & .643 & .688 & .879 & .640 \\
\hline \multirow{4}{*}{$\begin{array}{l}\text { Intention to Adopt } \\
\text { (ITA) }\end{array}$} & $\cdot$ ITA1 & .592 & .578 & .586 & .655 & .515 & .460 & .658 & .578 & .582 & .592 & .728 & .928 \\
\hline & $\cdot$ ITA2 & .528 & .586 & .544 & .606 & .527 & .449 & .636 & .532 & .565 & .592 & .706 & .921 \\
\hline & $\cdot$ ITA3 & .588 & .578 & .576 & .657 & .481 & .409 & .582 & .581 & .570 & .568 & .687 & .937 \\
\hline & $\cdot$ ITA4 & .572 & .532 & .532 & .625 & .516 & .408 & .590 & .550 & .574 & .596 & .710 & .935 \\
\hline
\end{tabular}

$E i G$, Enjoyment in Gamification; $C T i G$, Creative Thinking in Gamification; $A i G$, Activation in Gamification; $M R$, Media Richness; $U$, Usefulness; $E O U$, Ease of Use; $P V$, Perceived Value; $I T$, Interactivity; $P R$, Presence; IMS, Immersion; SA, Satisfaction; ITA, Intention to Adop

With a design of creating enjoyable, energized, and activated user experience, VR can keep consumers not only interested, but also informed with more reliable, faster, and more interactive information before going to the destination. Therefore, VR make it contactless under COVID-19 by providing the participants with better information search and preexperiencing the destination. Consumers had a more detailed destination image as well as minimize the risk related to high expectations, and may reduce the uncertainty of consumers buying tours online.

Second, both usefulness and ease of use are found to be positively influenced by media richness. These findings suggest a higher degree of communication ability in delivering 


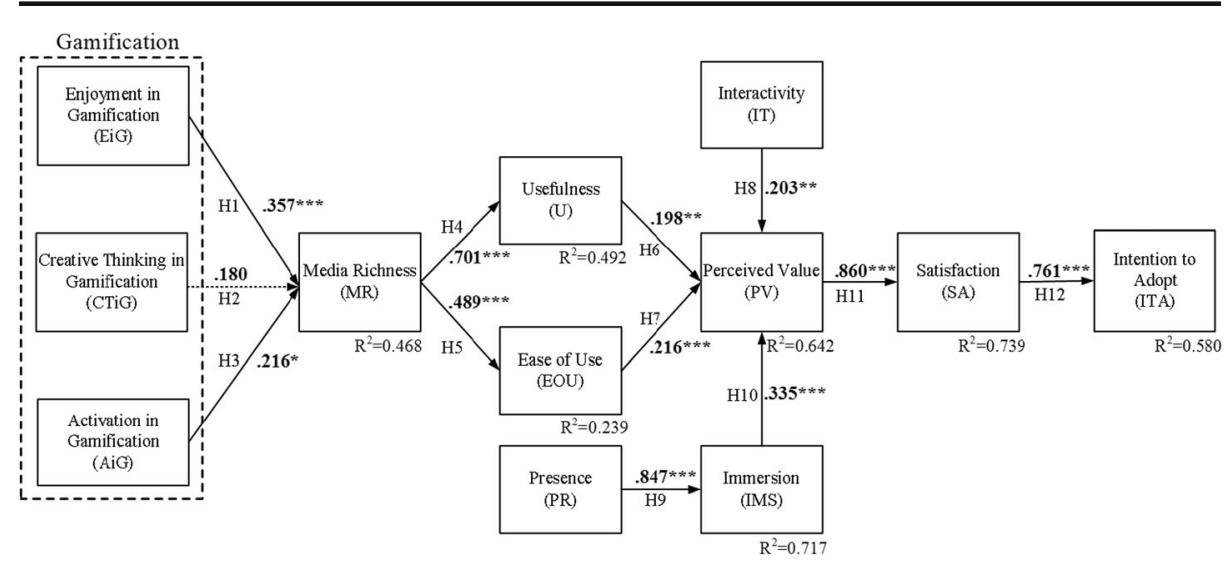

Fig. 6 The empirical study results

and processing the information provided by the medium (i.e., the proposed gamified VRTWS) would positively influence a user's perception on usefulness and ease of use in adopting the proposed system. Previous studies highlighted the points that users' perception on usefulness and ease of use would help increase technology adoption as well as new types of information, interaction, and business models. However, will this apply to the VR technologies under the context of COVID-19? According to the results in this study, through the positive impact on media richness, enjoyment and activation in gamification would have indirect effect on usefulness and ease of use. Therefore, online tourism service providers (i.e., travel agencies who have websites or apps) may consider offering an enjoyable and exciting gameful experience to their targeted users during the communication. This study provides a new lens for studying the adoption of the VR technologies under COVID-19 restrictions. VR practitioners are suggested to construct their VR tourism content by using advanced techniques such as $360^{\circ}$ scene creation technologies and incorporating game elements.

Table 5 Structural model (inner model) results

\begin{tabular}{|c|c|c|c|c|c|}
\hline $\mathrm{H}_{0}$ & Hypothesis & Path coefficient & $t$-statistics & $p$ value & Hypothesis test result \\
\hline $\mathrm{EiG} \rightarrow \mathrm{MR}$ & H1 & $0.357 * * *$ & 3.990 & 0.000092 & supported \\
\hline $\mathrm{CTiG} \rightarrow \mathrm{MR}$ & $\mathrm{H} 2$ & 0.180 & 1.840 & 0.067200 & not supported \\
\hline $\mathrm{AiG} \rightarrow \mathrm{MR}$ & H3 & $0.216^{*}$ & 2.005 & 0.046266 & supported \\
\hline $\mathrm{MR} \rightarrow \mathrm{U}$ & $\mathrm{H} 4$ & $0.701 * * *$ & 16.613 & 0.000000 & supported \\
\hline $\mathrm{MR} \rightarrow \mathrm{EOU}$ & H5 & $0.489 * * *$ & 8.680 & 0.000000 & supported \\
\hline $\mathrm{U} \rightarrow \mathrm{PV}$ & H6 & $0.198 * *$ & 2.639 & 0.008948 & supported \\
\hline $\mathrm{EOU} \rightarrow \mathrm{PV}$ & H7 & $0.216^{* * * *}$ & 3.784 & 0.000202 & supported \\
\hline $\mathrm{IT} \rightarrow \mathrm{PV}$ & $\mathrm{H} 8$ & $0.203^{* *}$ & 2.794 & 0.005695 & supported \\
\hline $\mathrm{PR} \rightarrow \mathrm{IMS}$ & H9 & $0.847 * * *$ & 40.265 & 0.000000 & supported \\
\hline $\mathrm{IMS} \rightarrow \mathrm{PV}$ & $\mathrm{H} 10$ & $0.335 * * *$ & 4.248 & 0.000033 & supported \\
\hline $\mathrm{PV} \rightarrow \mathrm{SA}$ & H11 & $0.860 * * *$ & 37.734 & 0.000000 & supported \\
\hline $\mathrm{SA} \rightarrow$ ITA & H12 & $0.761^{* * * *}$ & 17.854 & 0.000000 & supported \\
\hline
\end{tabular}

(1) $* p<0.05, * * p<0.01, * * * p<0.001$;

(2) $E i G$, Enjoyment in Gamification; $C T i G$, Creative Thinking in Gamification; AiG, Activation in Gamification; $M R$, Media Richness; $U$, Usefulness; $E O U$, Ease of Use; $P V$, Perceived Value; $I T$, Interactivity; $P R$, Presence; IMS, Immersion; SA, Satisfaction; ITA, Intention to Adopt 
Third, a user's perceived value is positively influenced by usefulness, ease of use, interactivity, and immersion. Among them, immersion, with a larger path coefficient $\left(0.335^{*}\right)$, is found to have the strongest effect on the perceived value of a user. This implies immersive experience, which is hard for a user to acquire in conventionally ordinary tourism websites, may serve as an important factor in enhancing the user's perceived value in VR contexts. This finding is similar to a prior study in identifying the importance of immersion in comparing immersive and non-immersive conditions [55]. In addition, through the strong effect on immersion (with a path coefficient of $0.847 * * *$ ), presence is found to have indirect and positive impact on a user's perceived value. As presence describes the realism level perceived by the users based on their relative information on the physical environment as well as indirect environment (such as in a VR context), providing a better experience of presence would help a user to reach a higher level immersive state and concentrate his or her attention on specific tasks in the system, thus leading to a higher perceived value. Consequently, under COVID-19, if users begin to enjoy a VR-driven destination at home more frequently because many countries have adopted "Stay at Home" policy, then it is a good opportunity for tourism service providers to create new tour services and a new market about inaccessible destinations through VR, e.g., heritage sites, jungles, or the North Pole.

Moreover, on the basis of the results, providing a useful and easy-to-use service system to a user would increase his or her perceived value. Although research contexts are different, these findings are consistent with prior studies $[7,25,28,34,59,93]$ in validating the relationships between usefulness, ease of use, and perceived value. Furthermore, the results suggest that a user with a higher degree of control in interacting with the service system would also consider the proposed system more valuable. Improving interactivity in the interaction process between users and the service system becomes an important issue to the online tourism service providers. Last but not least, through the positive impact on satisfaction, a user's perceived value has been confirmed to have a positive and indirect impact on intention to adopt.

Although prior study results have demonstrated the importance of satisfaction and its positive effect on the intention toward adoption [7], under different contexts, this study contributes to validating the relationships under the proposed gamified VRTWS with the combination of gamification elements and VR context in delivering tourism service online. Thus, to increase the intention of adoption, tourism service providers are suggested to focus on the enhancement of users' perceived value and satisfaction. As a result, we justify the effectiveness of VR as promotional purposes under COVID-19, this study reveals the interaction through VR affects users' intention to visit the destinations.

Revealed by our empirical study results, the hypothesis $\mathrm{H} 2$ was founded unsupported. This study results revealed that creative thinking in gamification does not significantly affect media richness. Media richness may not be affected because the context itself was set for tourism services. Although we created and provided a VR environment for the users, it is still different from the view of ordinary video games (e.g., Mario) that are intentionally created to be imaginative in many ways such as strange characters, cool stories, and gorgeous effects. The creation of the tourism attraction is realistic for providing the users a better sense of presence in their experience using the service. Therefore, our designed games with realistic display of the tourism attractions in the study context of VRTWS may result in the insignificant impact on media richness. 


\section{Implications, conclusion, and limitations \& future research}

\subsection{Implications}

On the basis of the proposed system (a gamified VRTWS) and the study results, several implications are suggested to be referenced by the system designer, developers, marketers, and managers in the tourism industry (such as online tourism service providers and the traditional travel agencies who provide web services) in managing the tasks of incorporating gamification into designing, developing, and managing their VR service application. First, as users (potential consumers) tend to adopt the service with the delivered information based on their perceived value and satisfaction, tourism managers are suggested to add the VR function for travel preview on the website. This may increase the number of people who are willing to go to visit the tourism destination presented in VR. Second, travel agencies need to improve the website usefulness and ease of use in order to generate higher value for consumers. According to this study, travel agencies can effectively increase consumer-perceived usefulness and ease of use by increasing the richness of media. To increase the richness, travel agencies can add gamification elements to the process of previewing in VR. Not only can it make consumers feel entertained, but it also stimulates consumers' imagination and vitality, which may give them a better preview experience. In turn, this increases the richness of media and makes consumers perceive higher usefulness and ease of use, thus make them perceive value. For example, the VR preview process applied in this study incorporates game elements, activates the consumer's motivation, and allows consumers to entertain and generate their own ideas during the preview process, making them feel that this application is useful to them and is easy to use. Third, when designing VR, travel agencies can increase the interaction of consumers in the virtual world because it will increase the consumer's perceived value - for example, with the design that allows consumers to move in the virtual space or operate objects in the virtual world through the controller, or increased interactivity between consumers and VR application, through which consumers can get more feedback from the application. These will make consumers feel more value with VR for travel previews. In the case of this study, our virtual world allows consumers to see the scene in the virtual world from different angles, and when the consumer clicks on a specific object, it will jump out of the text that describes the object, letting consumers get feedback and enabling them to gain useful information by interacting with VR, thereby making consumers feel the VR application is valuable. Fourth, during the period of COVID-19 pandemics, many countries have adopted "Stay at Home" policy with various restrictions on people's physical traveling [37]. People are not allowed to physically visit their desired travel attractions at this moment. Alternatively, they may rely more heavily on the Internet for desired tourism information. Using VR-enhanced tourism web system would help to add value to traditional travel websites in tourism e-commerce, while incorporating gamification could provide consumers enjoyable and activated experience without making them feel bored. Finally, for the travel agencies in some re-opened countries, it is suggested that they may provide suitable environment (avoid noisy environment) and equipment, such as VR helmets and controllers, to allow consumers to enter an immersive state in experiencing travel previews. These suggestions may help increase the consumer's immersive experience, and when consumers have immersive tour preview experience, it will in turn increase consumer's perceived value. Besides, according to the results of this study, the presence will also affect the immersion of consumers' tour preview experience. Therefore, this study suggests that the quality of the scene in the virtual world must be of a certain quality, 
and using high-resolution $360^{\circ}$ picture to construct VR content can help make the consumer perceive a higher sense of presence. Adding background sounds, such as sound of the wind or running water can also give consumers a more realistic experience and in turn make it easier for consumers to have an immersive experience. In summary, using VR for travel preview can ease some problems on traditional travel websites and may increase the number of people who are willing to go to visit the tourism destination presented in VR on the website. Thus, this study suggests that travel agencies pay attention to using VR application in tourism. Adding a VR application with gamified design to the travel website can help tourism service providers understand potential tourists' intention to visit the tourism destination. When consumers feel more perceived value about visiting the tourism destination, their willingness to go to and recommend the tourism destination presented in VR would be increased. This in turn would provide opportunity to travel agencies and reduce the uncertainty of consumers buying tours online.

\subsection{Conclusion}

This study contributed to exploring how gamification and VR-enhanced web services can be integrated to influence consumer behavior in tourism e-commerce. A gamified VR-enhanced tourism web system (VRTWS) was developed and a research framework (with 12 hypotheses) was proposed for this investigation. Our empirical findings revealed that: (1) both Enjoyment and Activation in Gamification significantly and positively affected Media Richness, (2) Media Richness significantly and positively affected both Usefulness and Ease of Use in using VR technology with gamification, (3) a user's Perceived Value is not only positively affected by Usefulness and Ease of Use but also Interactivity and Immersion in a gamified VRTWS, (4) Immersion was found to be positively affected by Presence, (5) through the positive effect on Satisfaction, user's Perceived Value had positive effect on the Intention toward adoption. In addition to the contribution regarding the research framework, the study also contributes to proposing a three-level system design philosophy for different technical level as well as the architecture for the proposed gamified VRTWS. Level I refers to the Tourism Web System (TWS) that provides conventional information and services for tourism products. Most of the ordinary tourism websites (e.g., https://en.liontravel.com/, an iconic tourism website in Taiwan) belong to this category, in which users only can use the browser on their PCs or mobile devices to check tourism information. Level II refers to the VR-enhanced Tourism Web System (VRTWS) that provides VR feature (without gameful experience) plus conventional information and services for tourism products. In this level, the VRTWS does not just typically show the pictures and itinerary information for tourism attractions but also has the ability to provide an embedded VR function and content in creating a better immersive tour preview experience. Level III refers to the Gamified VRTWS that further incorporates game elements and provides gameful experience to the users based on the foundation of VRTWS. By referring to the proposed three-level system design principle, current travel e-commerce companies are allowed to re-examine their current positions more clearly, set up their future direction, and formulate the development strategies (e.g., moving among Level I, II and III) based on their customer needs and market segmentation. For VR technical service firms, not only can they integrate downwards with the existing Level I tourism e-commerce companies, but they can also further incorporate gamification into VRTWS for upward development to Level III. The proposed gamified VRTWS, the validated research framework, the three-level system design philosophy and architecture, and the study results with implications can be 
referenced by the researchers and practitioners for managing incorporation of gamification into designing, developing, and managing their VR-enhanced service in tourism e-commerce.

\subsection{Limitations and future research}

There are several limitations in interpreting the results of the present study. First, of the 208 usable respondents in this study, $150(72 \%)$ were in the 15-20 years age group, because of the nature of convenience sampling at the management college of our university. The main participants fit well with those potential younger generations tourists who plan trips, and highly accept the delivered marketing information online, show the most interest in using VR [65]. Two hundred and eight (100\%) participants have been the users in searching for tourism information on the Internet for at least 3 years. In addition, partial least squares is a well-known method to detect statistically meaningful results [27]. The convergent validity and discriminant validity of the study was concluded to be supported by Table 3 and Table 4, and the current sample is unlikely to be a significant threat to the validity of the study. However, the COVID19 has different impacts on tourism industry (such as online tourism service providers and the traditional travel agencies who provide web services) based on their size, location, management and ownership style, and heterogeneous tourism demand (e.g. corporate travelers, leisure and business travelers, group and independent tourists, religious tourists, etc.). Hence, the future research should consider different samples to investigate different market segments. Next, in this study, we designed and developed the gamified VRTWS for users to experience Dali Art Plaza which is an emerging hot sightseeing spot in Taiwan. Since this study does not consider the impact of the variety of tourism experiences (e.g., visiting museums, amusement park, shopping, etc.) and gamification mechanisms (e.g., different rules, processes, or goals), future research can expand the experiment by implementing different destinations of VR experiences with different gamification mechanisms. Third, each participant was asked to fill in the research questionnaires immediately after experiencing the gamified VRTWS. Therefore, we rely on participants' recall of the VR experience instead of experienced during VR. Future research can use sensors and psychophysiological analysis to eliminate potential bias about the objective measurements of presence and enjoyment in gamification. Last, we designed and developed a tourism e-commerce web system (with embedded VR function and LazyDoor as the brand name) which is different from conventional online tourism websites that typically show pictures and itinerary information for tourism attractions. The aim of this study is to verify gamification and VR enriched the ordinary tourism websites' marketing in today's highly competitive and fast-changing e-tourism environment. Future research can extend to include a control group (without gamification and VR) to compare with the outcomes of the experimental group (users involved in the gamified VR-based application) to explain more broadly about consumer behavior in tourism e-commerce.

\section{References}

1. Agogué M, Levillain K, Hooge S (2015) Gamification of creativity: exploring the usefulness of serious games for ideation. Creat Innov Manag 24(3):415-429

2. Airbnb (2019) Airbnb: vacation rentals, homes, experiences \& places. Airbnb, Inc. https://www.airbnb. com. 
3. Ali F, Amin M, Cobanoglu C (2016) An integrated model of service experience, emotions, satisfaction, and price acceptance: an empirical analysis in the Chinese hospitality industry. J Hosp Mark Manag 25(4): 449-475

4. Aratuo DN, Etienne XL (2019) Industry level analysis of tourism-economic growth in the United States. Tour Manag 70:333-340

5. Ashraf AR, Thongpapanl NT, Spyropoulou S (2016) The connection and disconnection between ecommerce businesses and their customers: exploring the role of engagement, perceived usefulness, and perceived ease-of-use. Electron Commer Res Appl 20:69-86

6. Barclay D, Higgins C, Thompson R (1995) The partial least squares (PLS) approach to casual modeling: personal computer adoption ans use as an illustration.

7. Belanche D, Casaló LV, Guinalíu M (2012) Website usability, consumer satisfaction and the intention to use a website: the moderating effect of perceived risk. J Retail Consum Serv 19(1):124-132

8. Biocca F, Levy MR (2013) Communication in the age of virtual reality. Routledge

9. Bojanic DC (1996) Consumer perceptions of price, value and satisfaction in the hotel industry: an exploratory study. J Hosp Leis Mark 4(1):5-22

10. Brackett LK, Carr BN (2001) Cyberspace advertising vs. other media: consumer vs. mature student attitudes. J Advert Res 41(5):23-32

11. Cao K, Yang Z (2016) A study of e-commerce adoption by tourism websites in China. J Destin Mark Manag 5(3):283-289

12. Carlson JR, Zmud RW (1999) Channel expansion theory and the experiential nature of media richness perceptions. Acad Manag J 42(2):153-170

13. Chalhoub E, Tanos V, Campo R, Kesrouani A, El Rassy E, Rizkallah J, Chalhoub D, Walter C, Sleiman Z (2016) The role of video games in facilitating the psychomotor skills training in laparoscopic surgery. Gynecol Surg 13(4):419-424

14. Charfi AA (2014) Immersion and perceived value: the strategic variables for commercial websites. International Journal of Online Marketing (IJOM) 4(4):17-35

15. Chen JH, Fu J-R (2018) On the effects of perceived value in the mobile moment. Electron Commer Res Appl 27:118-128

16. Chen K, Yen DC, Hung S-Y, Huang AH (2008) An exploratory study of the selection of communication media: the relationship between flow and communication outcomes. Decis Support Syst 45(4):822-832

17. Chin WW, Marcolin BL, Newsted PR (2003) A partial least squares latent variable modeling approach for measuring interaction effects: results from a Monte Carlo simulation study and an electronic-mail emotion/ adoption study. Inf Syst Res 14(2):189-217

18. Chniti NA, Bouslama N (2015) Effects of perceived interactivity on commercial web sites' experiential value. International Journal of Innovation and Scientific Research 16(12):514-525

19. Cho B, Lee C, Chon T (2004) Effect of customers' service quality satisfaction for repurchase of golf range user. J Phys Educ 42(2):179-188

20. Choi JH, Han EY, Kim BR, Kim SM, Im SH, Lee SY, Hyun CW (2014) Effectiveness of commercial gaming-based virtual reality movement therapy on functional recovery of upper extremity in subacute stroke patients. Ann Rehabil Med 38(4):485

21. Chung N, Lee H, Lee SJ, Koo C (2015) The influence of tourism website on tourists' behavior to determine destination selection: a case study of creative economy in Korea. Technol Forecast Soc Chang 96:130-143

22. CoSpaces.io (2020) CoSpaces.io. https://cospaces.io/.

23. Csıkszentmihályi M (1975) Beyond boredom and anxiety. Jossey-Bass, San Francisco, CA

24. Daft RL, Lengel RH (1986) Organizational information requirements, media richness and structural design. Manag Sci 32(5):554-571

25. Davis FD (1989) Perceived usefulness, perceived ease of use, and user acceptance of information technology. MIS Quarterly:319-340

26. Dennis AR, Kinney ST (1998) Testing media richness theory in the new media: the effects of cues, feedback, and task equivocality. Inf Syst Res 9(3):256-274

27. do Valle PO, Assaker G (2016) Using partial least squares structural equation modeling in tourism research: a review of past research and recommendations for future applications. J Travel Res 55(6): 695-708

28. Ducoffe RH (1995) How consumers assess the value of advertising. J Curr Issues Res Advert 17(1):1-18

29. Elliott MT, Speck PS (1998) Consumer perceptions of advertising clutter and its impact across various media. J Advert Res 38(1):29-30

30. Eppmann R, Bekk M, Klein K (2018) Gameful experience in gamification: construction and validation of a Gameful experience scale [GAMEX]. J Interact Mark 43:98-115

31. Expedia (2018) Generations on the Move: A deep dive into multi-generational travel trends and how their habits will impact the future of the industry. 
32. Fornell C, Larcker DF (1981) Evaluating structural equation models with unobservable variables and measurement error. J Mark Res 18(1):39-50

33. Gale B, Wood RC (1994) Managing customer value: creating quality and service that customers can see. Simon and Schuster

34. Gefen D, Straub DW (2000) The relative importance of perceived ease of use in IS adoption: a study of ecommerce adoption. J Assoc Inf Syst 1(1):8

35. Gefen D, Straub D (2005) A practical guide to factorial validity using PLS-graph: tutorial and annotated example. Commun Assoc Inf Syst 16(1):5

36. Gilmore JH, Pine BJ (2007) Authenticity: what consumers really want. Harvard Business Press

37. Gostin LO, Wiley LF (2020) Governmental public health powers during the COVID-19 pandemic: stay-athome orders, business closures, and travel restrictions. Jama 323(21):2137-2138

38. Guttentag DA (2010) Virtual reality: applications and implications for tourism. Tour Manag 31(5):637651

39. Hair J Jr, Sarstedt M, Hopkins LG, Kuppelwieser V (2014) Partial least squares structural equation modeling (PLS-SEM) an emerging tool in business research. Eur Bus Rev 26(2):106-121

40. Hair JF Jr, Hult GTM, Ringle C, Sarstedt M (2016) A primer on partial least squares structural equation modeling (PLS-SEM). Sage publications

41. Hair JF Jr, Sarstedt M, Ringle CM, Gudergan SP (2017) Advanced issues in partial least squares structural equation modeling. Sage Publications

42. Hakak S, Noor NFM, Ayub MN, Affal H, Hussin N, Imran M (2019) Cloud-assisted gamification for education and learning-recent advances and challenges. Comput Electr Eng 74:22-34

43. Harwood T, Garry T (2015) An investigation into gamification as a customer engagement experience environment. J Serv Mark 29(6/7):533-546

44. Hasan B (2006) Delineating the effects of general and system-specific computer self-efficacy beliefs on IS acceptance. Inf Manag 43(5):565-571

45. Heinrichs JH, Lim J-S, Anghelescu H, Utz J (2008) Testing an integrated model of e-learning adoption decision. American Journal of Business Research (AJBR) 1(1):21-40

46. Hosseini M, Swaminathan V (2016) Adaptive 360 VR video streaming: Divide and conquer. In: 2016 IEEE International Symposium on Multimedia (ISM), IEEE, pp 107-110

47. Hsieh JP-A, Rai A, Keil M (2008) Understanding digital inequality: Comparing continued use behavioral models of the socio-economically advantaged and disadvantaged. MIS Quarterly:97-126

48. Hsu M-H, Chiu C-M (2004) Internet self-efficacy and electronic service acceptance. Decis Support Syst $38(3): 369-381$

49. Hua N (2016) E-commerce performance in hospitality and tourism. Int J Contemp Hosp Manag 28(9): 2052-2079

50. Insights $\mathrm{G}$ (2019) Virtual reality statistics.

51. Islam M, Kang M (2013) Yang S-B a research to identify the relationship between Consumers' attitude and Mobile advertising. PACIS, In, p 39

52. Jacob C, Guéguen N, Petr C (2010) Media richness and internet exploration. Int J Tour Res 12(3):303-305

53. Jalil NAA, Fikry A, Zainuddin A (2016) The impact of store atmospherics, perceived value, and customer satisfaction on behavioural intention. Procedia Economics Finance 37:538-544

54. Jang Y-T, Chang SE, Chen P-A (2015) Exploring social networking sites for facilitating multi-channel retailing. Multimed Tools Appl 74(1):159-178

55. Jennett C, Cox AL, Cairns P, Dhoparee S, Epps A, Tijs T, Walton A (2008) Measuring and defining the experience of immersion in games. International Journal of Human-Computer Studies 66(9):641-661

56. Jung T, tom Dieck MC, Lee H, Chung N (2016) Effects of virtual reality and augmented reality on visitor experiences in museum. In: Information and Communication Technologies in Tourism 2016. Springer, pp $621-635$

57. Kalinauskas M (2014) Gamification in fostering creativity. Socialnès Technologijos 01:62-75

58. Kim T, Biocca F (1997) Telepresence via television: two dimensions of telepresence may have different connections to memory and persuasion. J Comput-Mediat Commun 3(2):JCMC325

59. Kim YJ, Han JY (2014) Why smartphone advertising attracts customers: a model of web advertising, flow, and personalization. Comput Hum Behav 33:256-269

60. Klook (2019) Klook travel: activities, tours, attractions and things to do. Klook Travel Technology Limited. https://www.klook.com.

61. Larcker DF, Lessig VP (1980) Perceived usefulness of information: a psychometric examination. Decis Sci 11(1):121-134

62. Lee W-j, Kim YH (2021) Does VR tourism enhance users' experience? Sustainability 13(2):806

63. Legris P, Ingham J, Collerette P (2003) Why do people use information technology? A critical review of the technology acceptance model. Inf Manag 40(3):191-204 
64. Lessiter J, Freeman J, Keogh E, Davidoff J (2001) A cross-media presence questionnaire: the ITC-sense of presence inventory. Presence: Teleoperators \& Virtual Environments 10(3):282-297

65. Li J, Yang M, Pan B (2015) Network analysis of navigation paths of tourists' trip planning and power structure of the online tourism in China. Asia Pacific journal of tourism research 20 (sup1):1451-1465

66. Lim J, Ayyagari R (2018) Investigating the determinants of telepresence in the e-commerce setting. Comput Hum Behav 85:360-371

67. Lim KH, Benbasat I (2000) The effect of multimedia on perceived equivocality and perceived usefulness of information systems. MIS Quarterly:449-471

68. Lin TT-C, Paragas F, Bautista JR (2016) Determinants of mobile consumers' perceived value of locationbased advertising and user responses. Int J Mob Commun 14(2):99-117

69. Liu Y, Shrum L (2009) A dual-process model of interactivity effects. J Advert 38(2):53-68

70. Liu S-H, Liao H-L, Pratt JA (2009) Impact of media richness and flow on e-learning technology acceptance. Comput Educ 52(3):599-607

71. Lohtia R, Donthu N, Hershberger EK (2003) The impact of content and design elements on banner advertising click-through rates. J Advert Res 43(4):410-418

72. Ltifi M (2018) Determinants of the intention of smartphone usage by mobile internet users for m-services. Manag Decis 56(11):2291-2307

73. Maity M, Dass M, Kumar P (2018) The impact of media richness on consumer information search and choice. J Bus Res 87:36-45

74. Martel E, Su F, Gerroir J, Hassan A, Girouard A (2015) Muldner K diving head-first into virtual reality: evaluating HMD control schemes for VR games. In, FDG

75. McMillan SJ, Hwang J-S (2002) Measures of perceived interactivity: an exploration of the role of direction of communication, user control, and time in shaping perceptions of interactivity. J Advert 31(3):29-42

76. McQuail D (1987) Mass communication theory: an introduction. Sage Publications, Inc

77. Mitchell AA, Olson JC (1981) Are product attribute beliefs the only mediator of advertising effects on brand attitude? J Mark Res 18(3):318-332

78. Murray D, Howat G (2002) The relationships among service quality, value, satisfaction, and future intentions of customers at an Australian sports and leisure Centre. Sport Management Review 5(1):25-43

79. Mütterlein J (2018) The three pillars of virtual reality? Investigating the roles of immersion, presence, and interactivity. In: Proceedings of the 51st Hawaii International Conference on System Sciences, pp 14071415

80. Novak TP, Hoffman DL, Yung Y-F (2000) Measuring the customer experience in online environments: a structural modeling approach. Mark Sci 19(1):22-42

81. Oliver RL (1980) A cognitive model of the antecedents and consequences of satisfaction decisions. J Mark Res 17(4):460-469

82. Patterson PG, Spreng RA (1997) Modelling the relationship between perceived value, satisfaction and repurchase intentions in a business-to-business, services context: an empirical examination. Int J Serv Ind Manag 8(5):414 434

83. Payne AF, Storbacka K, Frow P (2008) Managing the co-creation of value. J Acad Mark Sci 36(1):83-96

84. Petrick JF, Backman SJ (2002) An examination of the construct of perceived value for the prediction of golf travelers' intentions to revisit. J Travel Res 41(1):38-45

85. Rafaeli S (1988) From new media to communication. Sage Annual Review of Communication Research: Advancing Communication Science 16:110-134

86. Rahi S, Ghani MA (2019) Does gamified elements influence on user's intention to adopt and intention to recommend internet banking? Technology, The International Journal of Information and Learning

87. Raybourn EM, Deagle E (2005) Mendini K. Heneghan J Adaptive thinking \& leadership simulation game training for special forces officers. In, The Interservice, Industry Training, Simulation \& Education Conference (ITSEC)

88. Riedl MO, Stern A, Dini D, Alderman J (2008) Dynamic experience management in virtual worlds for entertainment, education, and training. International Transactions on Systems Science and Applications, Special Issue on Agent Based Systems for Human Learning 4(2):23-42

89. Ringle CM, Sarstedt M, Straub D (2012) A critical look at the use of PLS-SEM in MIS quarterly. MIS Quarterly (MISQ) 36(1)

90. Saarijärvi H, Kannan P, Kuusela H (2013) Value co-creation: theoretical approaches and practical implications. Eur Bus Rev 25(1):6-19

91. Saeed KA, Abdinnour-Helm S (2008) Examining the effects of information system characteristics and perceived usefulness on post adoption usage of information systems. Inf Manag 45(6):376-386

92. Saeed N, Sinnappan S (2009) Effects of media richness on user acceptance of web 2.0 technologies in higher education. Advanced Learning:233-244 
93. Scharl A, Dickinger A, Murphy J (2005) Diffusion and success factors of mobile marketing. Electron Commer Res Appl 4(2):159-173

94. Schierz PG, Schilke O, Wirtz BW (2010) Understanding consumer acceptance of mobile payment services: an empirical analysis. Electron Commer Res Appl 9(3):209-216

95. Shavitt S, Lowrey P, Haefner J (1998) Public attitudes toward advertising: more favorable than you might think. J Advert Res 38(4):7-22

96. Sherman WR, Craig AB (2018) Understanding virtual reality: Interface, application, and design. Morgan Kaufmann

97. Sigala M (2017) Collaborative commerce in tourism: implications for research and industry. Curr Issue Tour 20(4):346-355

98. Skadberg YX, Skadberg AN, Kimmel JR (2004) Flow experience and its impact on the effectiveness of a tourism website. Information Technology Tourism 7(3-4):147-156

99. Steuer J (1992) Defining virtual reality: dimensions determining telepresence. J Commun 42(4):73-93

100. Sweeney JC, Soutar GN (2001) Consumer perceived value: the development of a multiple item scale. J Retail 77(2):203-220

101. Tenenhaus M, Vinzi VE, Chatelin Y-M, Lauro C (2005) PLS path modeling. Computational Statistics \& Data Analysis 48(1):159-205

102. Teo H-H, Oh L-B, Liu C, Wei K-K (2003) An empirical study of the effects of interactivity on web user attitude. International Journal of Human-Computer Studies 58(3):281-305

103. Unity.com (2020) Unity Real-Time Development Platform | 3D, 2D VR \& AR Visualizations. https:// unity.com/.

104. Vatanparast R, Asil M (2007) Factors affecting the use of mobile advertising. International Journal of Mobile Marketing 2(2):21-34

105. Webster J, Trevino LK, Ryan L (1993) The dimensionality and correlates of flow in human-computer interactions. Comput Hum Behav 9(4):411-426

106. Weibel D, Wissmath B, Habegger S, Steiner Y, Groner R (2008) Playing online games against computervs. human-controlled opponents: effects on presence, flow, and enjoyment. Comput Hum Behav 24(5): 2274-2291

107. Witmer BG, Singer MJ (1998) Measuring presence in virtual environments: A presence questionnaire. Presence 7(3):225-240

108. WTTC (2018) Travel \& Tourism Economic Impact 2018 South East Asia. World Travel \& Tourism Council (WTTC) https://www.wttc.org/economic-impact/

109. Wu L (2019) Website interactivity may compensate for consumers' reduced control in E-commerce. J Retail Consum Serv 49:253-266

110. Wu S-I, Wei P-L, Chen J-H (2008) Influential factors and relational structure of internet banner advertising in the tourism industry. Tour Manag 29(2):221-236

111. $\mathrm{Xu} \mathrm{DJ}$ (2006) The influence of personalization in affecting consumer attitudes toward mobile advertising in China. J Comput Inf Syst 47(2):9-19

112. Yoo W-S, Lee Y, Park J (2010) The role of interactivity in e-tailing: creating value and increasing satisfaction. J Retail Consum Serv 17(2):89-96

113. Zeithaml VA (1988) Consumer perceptions of price, quality, and value: a means-end model and synthesis of evidence. J Mark 52(3):2-22

114. Zeithaml VA (1996) Services marketing. McGraw-Hill Education, Pvt Limited

115. Zhu G, Wu Z, Wang Y, Cao S, Cao J (2019) Online purchase decisions for tourism E-commerce. Electron Commer Res Appl: 100887

Publisher's note Springer Nature remains neutral with regard to jurisdictional claims in published maps and institutional affiliations. 